


\section{About IJMA [last updated October, $\left.1^{\text {st }}, 2021\right]$}

$\checkmark$ International Journal of Medical Arts is the Official Journal of the Damietta Faculty of Medicine, AlAzhar University, Egypt

$\checkmark$ It is an International, Open Access, Double-blind, Peer-reviewed Journal

$\checkmark$ Published four times a year

$\checkmark$ The First Issue was published in July 2019

$\checkmark$ Published under the following license: Creative Commons Attribution-ShareAlike 4.0 International Public License (CC BY-SA 4.0). It had updated from the Creative Commons license [CC BY] in volume 2, Issue 4, October 2020 About IJMA

$\checkmark$ The Egyptian Knowledge Bank hosts the web site of IJMA

$\checkmark$ The Egyptian Knowledge Bank supports IJMA

$\checkmark$ IJMA follows the regulations of the International Committee of Medical Journal Editors

$\checkmark$ IJMA is indexed in the "Directory of Open Access Journals" [15 January 2021].

$\checkmark$ IJMA is indexed in J-Gate [29-6-2021]

$\checkmark$ IJMA is a member of the International Society of Managing and Technical Editors

$\checkmark$ Listed in "Index Copernicus", "Publons", "Academic resource index [ResearchBib]" "Electronics journal library", "Eurasian Scientific Journal Index", "WorldCat" Superstar Journal Database, and "Citefactor"

$\checkmark$ IJMA introduced to the search engine [BASE] through DOAJ

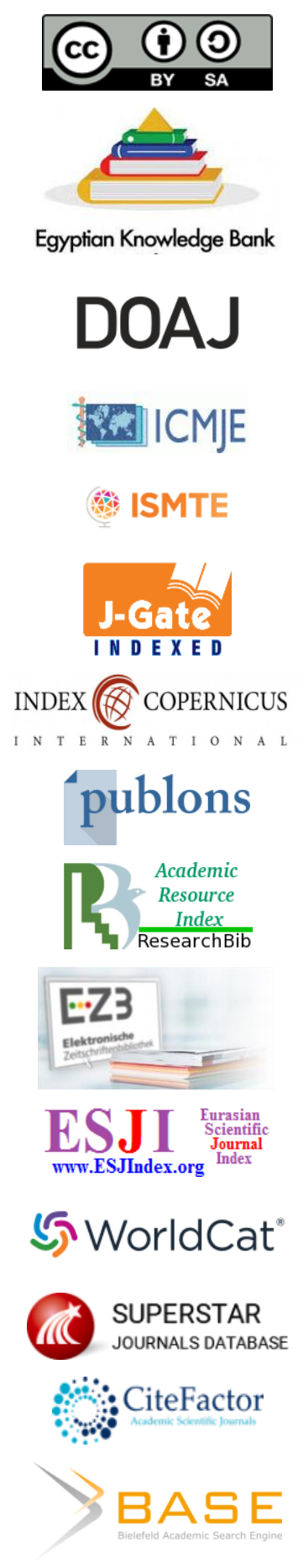




Available online at Journal Website
https://ijma.journals.ekb.eg/
Main subject [Obstetrics and Gynecology]

Original Article

\title{
Carbetocin versus Rectal Misoprostol to Decrease Blood Loss in Vaginal Delivery in High Risk Patients for Postpartum Hemorrhage
}

\author{
Yasmin Abd-Elmoaty Hetiba [1], Mahmoud salah Mahmoud [2], Abd Elraouf Mohammad Oun [2]
}

1 Department of Obstetrics and Gynecology, Dikrnis General Hospital, Ministry of Health, Egypt

2 Department of Obstetrics and Gynecology, Damietta Faculty of Medicine, Al-Azhar University, Egypt

\section{Corresponding author: Yasmin Abd-Elmoaty Hetiba}

Email: moon medicine@yahoo.com

Submission date: July 16, 2021; Acceptance date: November 6, 2021

DOI: $10.21608 / / J M A .2021 .86685 .1342$

DOAJ

ABSTRACT

Background: Postpartum hemorrhage is a critical complication after delivery. Methods to decrease or prevent postpartum hemorrhage continue to develop. The medical prophylaxis is frequently used with extension of the utilized drugs.

Aim of the work: The current study aims to evaluate the effects of intravenous carbetocin versus rectal misoprostol to decrease blood loss in vaginal delivery in high risk patients for postpartum hemorrhage.

Patients and Methods: The study included 94 Patients. They were selected from those attending for normal vaginal delivery and categorized as high risk for postpartum hemorrhage. All were evaluated on clinical basis, laboratory investigations and abdominal ultrasound. Then patients were randomly assigned into two equal groups; group A [Carbetocin group] received 1 ampoule of Carbetocin [100 $\mu \mathrm{g} / \mathrm{ml}]$ intravenously as a bolus injection slowly over one minute after neonatal delivery, and group B [Misoprostol group] received three rectal misoprostol tablets [600 $\mu \mathrm{g}]$ after neonatal delivery. Each group was assessed for hemodynamic changes [blood pressure, pulse and respiratory rate], gastrointestinal [GIT] side effects as nausea, vomiting and metallic taste, vasomotor effects as flushing, headache, itching.

Results: The amount of blood loss was significantly lower in the carbetocin group than in the misoprostol group [365.53 $\pm 41.12 \mathrm{ml}$ vs. $404.68 \pm 67.27 \mathrm{ml}]$. Need for uterotonics reported among $17.0 \%$ of misoprostol group compared to none [0.0\%] in carbetocin group [P=0.003]. On the other side, need for blood transfusion and uterine massage was also increased in misoprostol than carbetocin groups, but the difference was not statistically significant. The complications [drug side effects] revealed that, there was significant increase of fever, nausea \& vomiting, diarrhea and abdominal pain in misoprostol than carbetocin group [21.3\%, $10.6 \%, 19.14 \%$ and $21.3 \%$ vs. $0.0 \%, 0.0 \%, 2.12 \%$ and $0.0 \%$ successively].

Conclusion: Carbetocin is superior to misoprostol for postpartum hemorrhage, regarding efficacy and safety.

Keywords: Postpartum; Hemorrhage; Carbetocin; Misoprostol, Vaginal Delivery.

This is an open-access article registered under the Creative Commons, ShareAlike 4.0 International license [CC BY-SA 4.0] [https://creativecommons.org/licenses/by-sa/4.0/legalcode.

Citation: Hetiba YA, Mahmoud MS, Oun AM. Carbetocin versus Rectal Misoprostol to Decrease Blood Loss in Vaginal Delivery in High Risk Patients for Postpartum Hemorrhage. IJMA 2021; 3 [4] October-December: 1923-1929. [DOI: 10.21608/IJMA.2021.86685.1342].

* Main subject and any subcategories have been classified according to the research topic 
INTRODUCTION

Postpartum hemorrhage [PPH] diagnosis is settled when there is a blood loss of more than $500 \mathrm{ml}$ in the first 24 hours after normal vaginal delivery or more than one litre after cesarean delivery. PPH is a critical etiology of maternal complications and even death after delivery. Active PPH management by uterotonic drugs will reduce its rate [1].

Obstetric hemorrhage represents $25 \%$ of maternal mortality in the developing world and $\mathrm{PPH}$ is the commonest type. PPH is responsible for $10.6 \%$ of all United Kingdom direct maternal deaths, and it is the third common etiology of maternal deaths ${ }^{[2]}$. As a result, the use of uterotonics during cesarean delivery or in active management of the third stage of normal labor has become essential to reduce the risk of PPH and decrease maternal morbidity and mortality [3].

The World Health Organization endorses active management for the third stage of labor, and the use of uterotonic such as oxytocin should be used as a prophylaxis against PPH in all females at delivery ${ }^{[4]}$.

The first line medication for PPH is oxytocin administration; however, many studies reported that the sole administration of oxytocin is not sufficient and other non-drug methods are recommended. Other methods used to control PPH [not responded to oxytocin administration] include uterine massage, internal iliac artery ligation, uterine artery suturing, embolization, uterine package, and if not controlled, hysterectomy is the last resort [5].

There are further medications, other than oxytocin, to reduce or prevent $\mathrm{PPH}$. The timing of administration is crucial. A previous trial showed that the use of oxytocin or methylergometrine immediately after delivery of the anterior shoulder of the fetus can markedly decrease the rate of $\mathrm{PPH}$ when compared to the use of uterotonics after delivery of the placenta [6].

Carbetocin is used to control PPH. It is an oxytocinanalogue, binds to the same oxytocin receptors, on the uterus smooth musculature, leading to rhythmic uterine contractions, increased frequency of the existing contractions, and augments the uterine tone ${ }^{[7]}$. Misoprostol is a prostaglandin E1 [PGE1] analogue, producing its action through $G$ proteins which normally activate adenylate cyclase. The indirect inhibition of adenylate cyclase by misoprostol may be reliant on guanosine-5'triphosphate [GTP]. Misoprostol also augments the amplitude and frequency of uterine contractions during gestation ${ }^{[8]}$.

\section{AIM OF THE WORK}

Whatever the mechanism of action, the vital role for obstetrician is the prevention of PPH with minimal side effects. Thus, many drugs were tried continuously. The study aims at evaluating the effects of intravenous carbetocin versus rectal misoprostol to decrease blood loss in vaginal delivery in high risk patients for postpartum hemorrhage.

\section{PATIENTS AND METHODS}

The study was designed as a randomized comparative trial. It had been conducted at Obstetrics and Gynecology Department, Al-Azhar University [New Damietta] from December 2019 to December 2020. The study included 94 patients selected from those whom admitted for spontaneous or induced vaginal delivery and categorized as high risk for postpartum hemorrhage.

The inclusion criteria were high risk for postpartum hemorrhage [e.g., grand multiparity $>5$ deliveries], uterine over distension due to any reason, prolonged second stage of labor, patients with history of postpartum hemorrhage in previous deliveries, and medical disorders [e.g. Diabetes, anemia and coagulation disorders].

On the opposite side, the exclusion criteria were history of hypersensitivity to carbetocin or misoprostol, traumatic PPH and medical disorders [e.g. cardiovascular diseases especially coronary artery diseases, valvular heart diseases, cardiomyopathy and heart failure, hepatic, renal diseases, serious vascular disorders and epileptic patients].

All Patients were subjected to clinical evaluation by detailed history, physical examination [general and local for progress of labor], and laboratory investigations [Complete Count of blood cells, and determination of blood groups]. Additionally, all patients were evaluated by obstetric ultrasound for fetal viability, gestational age, estimated fetal weight [EFW] and placental site. Then patients were randomly subdivided [closed envelope method] into 2 groups [A and B]; each group include 47 patients: Group A [Carbetocin group] received 1 ampoule of Carbetocin [100 $\mu \mathrm{g} / \mathrm{ml}]$ [Pabal; Draxis, Multipharma, Egypt, under license from Draxis Pharma, Canada] intravenously as a bolus injection slowly over 1 minute after neonatal delivery. Group B [Misoprostol group] received three rectal misoprostol tablets [600 $\mu \mathrm{g}$, Misotac; Sigma Pharma, Cairo, Egypt] after neonatal delivery.

Blood samples were used to measure hemoglobin levels on admission to the delivery room and at 24 hours post-delivery. After parturition of the neonatal anterior 
shoulder, uterotonic agent [misoprostol or carbetocin] was administrated. Then, we clamped the umbilical cord and it was separated after birth. A minimal tension was applied on the cord with abdominal counter pressure to the uterus at the same time. If the uterus was in atony or there was uncontrollable bleeding within 5 minutes of drug administration, an additional uterotonic drug was administered [intramuscular methergin] with or without uterine message. The genital tract was thoroughly reviewed for detection and management of any tears [cervical or vaginal]. Any episiotomy [if carried out] was sutured. The measurement of blood loss was started directly after uterotonic drug administration.

\section{Calculation of blood loss}

The total volume of collected fluids in the underbuttocks towels was documented. The fluid volume collected in the towels was added to the volume measured by weighing soaked drapes. All blood-soaked drapes and clots were weighed to calculate cumulative volume. The equation used to calculate blood loss was wet items gram weight - the same dry item gram weight $=$ milliliters of blood [9].

Complete blood count was done to compare between the efficacies of each drug in decreasing blood loss. Each group was assessed for hemodynamic changes, GIT side effects, vasomotor effects, headache and itching.

\section{Sample Size}

The sample size was calculated using the following formula [10]:

$$
\mathrm{N}=\left\lfloor\frac{z \alpha}{2} \sqrt{2 p q}+\left.z \beta \sqrt{p 1 q 1+p 2 q 2}\right|^{2}\right.
$$

Where, $N=$ sample size, $z \alpha / 2=1.96$ [the critical value that divides the central $95 \%$ of the $z$ distribution from the $5 \%$ in the tail, $z \beta=1.96$ [the critical value that separate the lower $5 \%$ of the $z$ distribution from the upper $80 \%$ ], $p=$ [p1+p2]/2 [p1= proportional of bleeding $500 \mathrm{ml}$ of blood in patients treated with misoprostol $=47 \%, \mathrm{p} 2=$ proportional of bleeding $500 \mathrm{ml}$ of blood in patients treated with Carbetocin $=20 \%$ [11], $q=[1-p]$. So, the sample size is equal to 94 subject total 47 subjects per group.

\section{Ethical considerations}

This study was approved by Institution Research Board [IRB] of Damietta faculty of medicine Al-Azhar University. Informed verbal consent was obtained from each participant sharing in the study. Confidentiality and personal privacy will be respected in all levels of the study.

\section{Statistical analysis}

Data were analysed using Statistical Program for Social Science [SPSS] version 24. Quantitative data were expressed as mean \pm standard deviation [SD]. Qualitative data were expressed as frequency and percentage. The test used for comparison was Chi square test, student "t" test and paired samples' " $\mathrm{t}$ " test for appropriate data. Pvalue $<0.05$ was considered significant.

\section{RESULTS}

The age of the cases ranged from 15 years to 48 years with the mean age $30.02 \pm 7.68$ years. The mean gravidity number was $3.86 \pm 2.5$ times and the mean parity number was $2.13 \pm 1.78$ times. The mean body mass index for the participating cases was $30.59 \pm 4.6 \mathrm{~kg} / \mathrm{m}^{2}$. The mean hemoglobin measured before delivery for the cases was $10.41 \pm 1.4 \mathrm{~g} / \mathrm{dl}$. Two patients [2.13\%] were smokers, $6.38 \%$ had gestational hypertension, $3.19 \%$ had diabetes mellitus, $2.13 \%$ had hypternsion, $2.13 \%$ had chronic sinusitis, $1.06 \%$ had depression, $1.06 \%$ had chronic cholecystitis, $1.06 \%$ had hepatitis C-virus, and $1.06 \%$ had hypothyroidism. The obstetrics ultrasound revealed single viable fetus among $80.85 \%, 15.96 \%$ had dichorionic diamniotic viable twins, $2.13 \%$ had triplets viable and $1.06 \%$ had monochorionic monoamniotic viable twin. Results revealed that, $33.0 \%$ of patients had anemia, $9.6 \%$ had thrombocytopenia, $3.2 \%$ had polyhydramnios, the grand-multipara were $14.9 \%$, and history of previous PPH was reported among $16.0 \%$ and history of antepartum hemorrhage was reported among $18.1 \%$. The mean pulse measured for the participating cases was $72.8 \pm 7.9$ peat/minute. The mean systolic blood pressure measured for the cases was $104.8 \pm 10.9 \mathrm{mmHg}$. The mean diastolic blood pressure measured for the cases was $68.4 \pm 7.2$ $\mathrm{mmHg}$. The mean temperature measured for the cases was $37.3 \pm 0.5 \mathrm{C}^{\circ}$. The mean respiratory rate was $17.4 \pm 1.0$ breaths/minute. The mean hemoglobin measured after delivery for the cases was $10 \pm 1.2 \mathrm{~g} / \mathrm{dl}$. The mean amount of blood loss of cases was $385.1 \pm 58.8 \mathrm{cc}$. The need for uterotonics [methergin] was reported among $8.5 \%$, need for blood transfusion indicated in $17.0 \%$ and need for uterine massage among $17.0 \%$. Allergy reported among $2.1 \%$, fever in $10.6 \%$, nausea and vomiting among $5.3 \%$, diarrhea in $10.6 \%$, abdominal pain in $10.6 \%$, facial flushing in $19.1 \%$, and headache in $22.3 \%$.

There were no statistically significant difference between means of hemoglobin level before and after delivery in cases that had misoprostol and the cases that had carbetocin. On the other hand, the amount of blood loss showed a statistically significant difference between the cases that had misoprostol and the cases that had 
carbetocin as the mean was less in carbetocin group than in misoprostol group. Need for uterotonics reported among $17.0 \%$ of misoprostol group compared to none [0.0\%] in carbetocin group, with significant difference. On the other side, need for blood transfusion and uterine massage was also increased in misoprostol than carbetocin groups, but the difference was statistically non-significant. The complications [drug side effects] revealed that, there was significant increase fever, nausea and vomiting, diarrhea and abdominal pain misoprostol than carbetocin [Table 1].

Table [1]: Comparison between misoprostol and carbetocin groups regarding outcome

\begin{tabular}{lcccc}
\hline \multicolumn{1}{c}{ Variable } & & Group & P value \\
\cline { 2 - 4 } Hemoglobin & Before delivery & $10.11 \pm 1.40$ & $10.51 \pm 1.41$ & 0.17 \\
& 24 After delivery & $9.78 \pm 1.23$ & $10.18 \pm 1.22$ & 0.11 \\
Amount of blood loss [ml] & & $404.68 \pm 67.27$ & $365.53 \pm 41.12$ & $<0.001^{*}$ \\
Need for uterotonics [methergin] & $8[17.0 \%]$ & $0[0.0 \%]$ & $0.003^{*}$ \\
Need for blood transfusion & & $11[23.4 \%]$ & $5[10.6 \%]$ & 0.08 \\
Need for uterine massage & Allergy & $10[21.3 \%]$ & $6[12.8 \%]$ & 0.41 \\
Complications & Fever & $2[4.3 \%]$ & $0[0.0 \%]$ & 0.153 \\
& Nausea and vomiting & $10[21.3 \%]$ & $0[0.0 \%]$ & $0.001^{*}$ \\
& Diarrhea & $5[10.6 \%]$ & $0[0.0 \%]$ & $0.022^{*}$ \\
& Abdominal pain & $9[19.14 \%]$ & $1[2.12 \%]$ & $0.007^{*}$ \\
& Facial flushing & $10[21.3 \%]$ & $0[0.0 \%]$ & $0.001^{*}$ \\
& Headache & $9[19.14 \%]$ & $9[19.14 \%]$ & 1.0 \\
\hline
\end{tabular}

\section{DISCUSSION}

$\mathrm{PPH}$ is the most common cause of maternal comorbidity and mortality. It is responsible for about $20 \%$ of maternal deaths worldwide [12]. The PPH could be due to uterine atony, retained placental parts, genital trauma and coagulopathies ${ }^{[13]}$. Uterine atony is the major etiology of $\mathrm{PPH}$ and is responsible for up to $70 \%$ of cases. As a result, several uterotonics are tried to prevent PPH, including oxytocin, ergot alkaloid and prostaglandin [14].

The current study focused on comparing between the effect of misoprostol and carbetocin on reducing loss of blood and prevention of PPH in high risk patients. The results in this study showed that neither administration of misoprostol nor Carbetocin had significant effect on the hemoglobin level. In line with the above results, a recent study by Ismail et al. ${ }^{14]}$ showed no significant difference between the carbetocin and misoprostol groups as regard mean change in hemoglobin level in the first day after treatment. Another study compared between carbetocin and misoprostol. The results showed that the hemoglobin was not significantly different between women who received carbetocin or misoprostol among women who had normal vaginal delivery. However, the hemoglobin levels were significantly reduced in misoprostol than carbetocin among females delivered by cesarean section [15]. In the same line, Attilakos et al. ${ }^{[16]}$ compared carbetocin and oxytocin: the results were not significant different and there was no difference in the mean hemoglobin after delivery.
Furthermore, a study done by Fazel et al. [17], compared between rectal misoprostol and IV oxytocin and the results showed that the reduction in hemoglobin level in the two groups wasn't statistically significant $[P=0.55]$.

In current study, the amount of blood loss was significantly less in the Carbetocin group [364.79 \pm 40.99 cc] than in misoprostol group [404.68 $\pm 67.24 \mathrm{cc}$ ] [p-value $=$ 0.001]. This is coincided with the results done by Abd El Aziz et al. [15]; the results revealed that blood loss was significantly lower in carbetocin than misoprostol groups among females delivered through normal vaginal delivery $[N V D]$ and those delivered by cesarean section.

In a study done by Mousa et al. ${ }^{18]}$ as they compared carbetocin, oxytocin and misoprostol; the mean blood loss was greater in the misoprostol than carbetocin group and the difference was statistically significant. Additionally, a recent research revealed that, blood loss was significantly lower in carbetocin than misoprostol among NVD as well as cesarean section groups ${ }^{[14]}$.

This is in line with Khalafalah ${ }^{[19]}$ as he found that the blood loss was $366.4 \pm 165$ in the carbetocin group and was $434.7 \pm 191.7$ in the misoprostol group [ $p=0.01]$. In another study done by Sallam and Shady [20], at Aswan University Hospital comparing misoprostol with placebo in reduced blood loss and prevention of PPH. It was found that high significant reduction in blood loss with misoprostol group than placebo group. 
In the current study, the need for uterotonic drugs was affected by the type of drug used for prevention of PPH where the cases that had carbetocin as a prophylactic against PPH did not need additional uterotonic drugs [pvalue $=0.003]$.

In a recent study, the researchers found that the need for additional uterotonics was significant between the groups. Their findings showed an increased use of additional oxytocics in the misoprostol group $[32 \%$ of cases] versus [12\% of cases] in carbetocin group [14]. This is in consistent with, Abd El-Wahab et al. [21], as the results showed that the need for other uterotonic drugs was less in carbetocin group than in misoprostol group as, nine of eighty cases needed additional uterotonic drugs in carbetocin group while in the misoprostol group twenty-five of eighty cases needed additional uterotonic drugs. Another randomized prospective study showed that the blood loss and the need for additional uterotonics were significantly lower with the use of carbetocin [22].

Ibrahim and Saad [23] performed prospective, randomized study and found that the need of extrauterotonic drugs and need for blood transfusion was significantly higher with misoprostol than carbetocin. In the same line, Larciprete et al. ${ }^{\text {24] }}$ compared carbetocin and oxytocin in high- risk patients who underwent caesarean section and they noted that carbetocin was associated with lower use of additional uterotonics. In addition, Attilakos et al. ${ }^{[16]}$ performed double-blind randomized study women at term undergoing elective or emergency caesarean section under spinal anesthesia; it was found that more women needed additional oxytocics in the oxytocin group significantly.

On the other hand, study by Elbohoty et al. [11] recorded no significant difference between carbetocin and misoprostol in the reduction of the risk of severe PPH. Also, Leung et al. ${ }^{[25]}$ performed prospective, double-blinded, randomized study on women with a singleton pregnancy achieving vaginal delivery beyond 34 -week gestation. The incidence of additional oxytocic injections was similar in the studied groups.

Regarding the need for blood transfusion the present study showed that it was not affected by the type of drug used. The above results were also noted by Maged et al. [22], as there was no significant difference between the carbetocin and oxytocin group regarding occurrence of major PPH, the need for blood transfusion. In addition, Attilakos et al. ${ }^{[16]}$ researchers found that there were no significant differences in the secondary outcomes, including major PPH and blood transfusions. This is contrary to other results where the need for blood transfusion was found to be higher with misoprostol as compared to carbetocin [23]. Also, Abd El-Wahab et al. [21] showed that the need for blood transfusion was different as in carbetocin group there wasn't any patient need blood transfusion versus 3 cases in misoprostol group need for blood transfusion.

In our research, the side effects showed heterogeneous results; some showed significance while others showed no difference. The cases that had side effects in the form of fever, nausea and vomiting, diarrhea and abdominal pain were found to be significant between misoprostol and carbetocin groups, where the cases in the carbetocin group were less likely to have these side effects after delivery. On the other hand, the cases that had adverse effects in the form of allergy, facial flushing and headache were found to be statistically not significant between misoprostol and carbetocin groups.

The results of different studies regarding side effects of drugs used to prevent PPH shows many conflicts and not consistent with each other. For instance, Abd El-Aziz et al. [15] stated that regarding side effects of drugs used to prevent PPH; the heart rate was higher in misoprostol than carbetocin. Additionally, the incidence of heat sensation, metallic taste, fever, and shivering were significantly higher in misoprostol than carbetocin. In addition, Su et al. [26] compared the effects of carbetocin to syntometrine and reported that side effects were more common in syntometrine than carbetocin.

Furthermore, Bellad et al. [27] performed double-blind randomized controlled trial consenting eligible pregnant females admitted to the labor room, and used sublingual misoprostol or oxytocin for prevention of PPH. Their results showed significantly lower side effects in the oxytocin than misoprostol group. Also, Ibrahim and Saad [23] reported the results regarding side effects, misoprostol was associated with shivering and pyrexia as compared to carbetocin while nausea, vomiting and headache were more associated with carbetocin.

A more recent study found that the side effects of drugs used to prevent PPH shows that abdominal pain, headache and tachycardia were more in carbetocin groups and the incidence of abdominal pain was less in misoprostol [21]. Another study presented by Leung et al. ${ }^{25]}$ clarified that the use of carbetocin was associated with significant lower incidence of nausea.

\section{CONCLUSION}

In conclusion, carbetocin was better than misoprostol for reducing postpartum blood loss in high-risk patients. It is associated with less use of additional uterotonic and fewer side effects. However, this conclusion should be cautiously 
considered, as the assessment of PPH is usually a subjective matter and small sample size of patients were included irrespective of sample size justification.

Financial and Non-financial Relationships and Activities of Interest

None

\section{REFERENCES}

1. McLintock C. Prevention and treatment of postpartum hemorrhage: focus on hematological aspects of management. Hematology Am Soc Hematol Educ Program. 2020 Dec 4; 2020 [1]: 542-546. doi: 10.1182/hematology.2020000139.

2. Benson G. Primary post-partum haemorrhage Causation and management. J Perioper Pract. 2019 Apr; 29[4]:75-80. doi: 10.1177/1750458918782902.

3. Gallos I, Williams H, Price M, Pickering K, Merriel A, Tobias A, et al. Uterotonic drugs to prevent postpartum haemorrhage: a network meta-analysis. Health Technol Assess. 2019 Feb; 23 [9]:1-356. doi: 10.3310/hta23090.

4. de Castro Parreira MV, Gomes NC. Preventing postpartum haemorrhage: active management of the third stage of labour. J Clin Nurs. 2013 Dec;22[2324]:3372-87. doi: 10.1111/jocn.12361.

5. Elbohoty AE, Mohammed WE, Sweed M, Bahaa Eldin AM, Nabhan A, Abd-El-Maeboud KH. Randomized controlled trial comparing carbetocin, misoprostol, and oxytocin for the prevention of postpartum hemorrhage following an elective cesarean delivery. Int J Gynaecol Obstet. $2016 \quad$ Sep;134[3]:324-8. doi: 10.1016/j.jgo.2016.01.025. Epub 2016 May 25. PMID: 27350226.

6. Lawrie TA, Rogozińska E, Sobiesuo P, Vogel JP, Ternent L, Oladapo OT. A systematic review of the cost-effectiveness of uterotonic agents for the prevention of postpartum hemorrhage. Int J Gynaecol Obstet. 2019 Jul;146[1]:56-64. doi: 10.1002/ijgo.12836.

7. Lucas DN, Meshykhi LS, Nel MR. The role of carbetocin in the prevention and management of postpartum haemorrhage - In reply. Int J Obstet Anesth. 2017 Nov;32:91. doi: 10.1016/j.ijoa.2017.06.002. Epub 2017 Jun 20. PMID: 28689623.

8. Awoleke JO, Adeyanju BT, Adeniyi A, Aduloju OP, Olofinbiyi BA. Randomised Controlled Trial of
Sublingual and Rectal Misoprostol in the Prevention of Primary Postpartum Haemorrhage in a ResourceLimited Community. J Obstet Gynaecol India. 2020 Dec;70[6]:462-470. DOI: 10.1007/s13224-020-01338-0.

9. ACOG. Quantitative Blood Loss in Obstetric Hemorrhage: ACOG COMMITTEE OPINION, Number 794. Obstet Gynecol. 2019 Dec;134[6]:e150-e156. DOI: 10.1097/AOG.00000000000003564. PMID: 31764759.

10. Dawson B, Trapp RG. Basic \& clinical biostatistics. In Basic \& clinical biostatistics. Lange Medical Books. New York: McGraw-Hill; 2004.

11. Elbohoty AE, Mohammed WE, Sweed M, Bahaa Eldin AM, Nabhan A, Abd-El-Maeboud KH. Randomized controlled trial comparing carbetocin, misoprostol, and oxytocin for the prevention of postpartum hemorrhage following an elective cesarean delivery. Int J Gynaecol Obstet. $2016 \quad$ Sep;134[3]:324-8. DOI: 10.1016/j.ijgo.2016.01.025.

12. Maged AM, Waly M, Fahmy RM, Dieb AS, Essam A, Salah NM, Hussein EA, Nabil H. Carbetocin versus rectal misoprostol for management of third stage of labor among women with low risk of postpartum hemorrhage. Int J Gynaecol Obstet. 2020 Feb;148[2]:238-242. DOI: 10.1002/ijgo.13056.

13. Sentilhes $L$, Vayssière $C$, Deneux-Tharaux $C$, Aya AG, Bayoumeu $F$, Bonnet MP, et al. Postpartum hemorrhage: guidelines for clinical practice from the French College of Gynaecologists and Obstetricians [CNGOF]: in collaboration with the French Society of Anesthesiology and Intensive Care [SFAR]. Eur $\mathrm{J}$ Obstet Gynecol Reprod Biol. 2016 Mar; 198:12-21. DOI: 10.1016/j.ejogrb.2015.12.012.

14. Ismail IA, Fahmy MS, Farouk HA. Carbetocin versus Misoprostol in Prevention of Postpartum Hemorrhage in High Risk Patients. Egy J Hospital Med. 2019; 77[2]: 4913-4919. DOI: 10.21608/ejhm.2019.47460.

15. Abd El Aziz MA, Iraqi A, Abedi P, Jahanfar S. The effect of carbetocin compared to misoprostol in management of the third stage of labor and prevention of postpartum hemorrhage: a systematic review. Syst Rev. 2018 Oct 20; 7[1]:170. DOI: 10.1186/s13643-0180832-4.

16. Attilakos G, Psaroudakis D, Ash J, Buchanan R, Winter $C$, Donald F, Hunt LP, Draycott T. Carbetocin versus oxytocin for the prevention of postpartum haemorrhage following caesarean section: the results of a doubleblind randomised trial. BJOG. 2010 Jul;117[8]:929-36. 
DOI: 10.1111/j.1471-0528.2010.02585.x.

17. Fazel MR, Mansoure-Samimi, Esmaeil-Fakharian. A comparison of rectal misoprostol and intravenous oxytocin on hemorrhage and homeostatic changes during cesarean section. Middle East J Anaesthesiol. 2013 Feb;22[1]:41-6. PMID: 23833849.

18. Mousa HA, Blum J, Abou El Senoun G, Shakur H, Alfirevic Z. Treatment for primary postpartum haemorrhage. Cochrane Database Syst Rev. 2014 Feb 13; $2014 \quad$ [2]:CD003249. DOI: 10.1002/14651858.CD003249.pub3.

19. Khalafalah MM. Oxytocin vs carbetocin in management of 3rd stage at risk of PPH. MOJ Women's Health. 2017;5[4]:271-275.

DOI: 10.15406/mojwh.2017.05.00131.

20. Sallam HF, Shady NW. Adjunctive sublingual misoprostol for secondary prevention of post-partum hemorrhage during cesarean delivery: double blind placebo randomized controlled trial. Int $\mathrm{J}$ Reprod Contracep Obstet Gynecol. 2018;7[2]:495-502. DOI: 10.18203/2320-1770.jircog20180161.

21. Abd El-Wahab SA, Ahmed KA, Marai AA. The effect of carbetocin compared to rectal misoprostol in the management of blood loss during the third stage of vaginal delivery in low risk patients for postpartum hemorrhage. Al-Azhar Med J. 2020; 49[4]: 1673-1682. DOI: 10.12816/amj.2020.120624.

22. Maged AM, Hassan AM, Shehata NA. Carbetocin versus oxytocin in the management of atonic post partum hemorrhage [PPH] after vaginal delivery: a randomized controlled trial. Arch Gynecol Obstet. 2016 May; 293[5]:993-9. DOI: 10.1007/s00404-015-3911-y.
23. Ibrahim KA, Saad AS. Prevention of postpartum haemorrhage in patients with severe preeclampsia using carbetocin versus misoprostol. Apollo Med. 2017; 14 [2]: 117-122. DOI: 10.1016/j.apme.2017.02.008

24. Larciprete G, Montagnoli C, Frigo M, Panetta V, Todde C, Zuppani B, et al. Carbetocin versus oxytocin in caesarean section with high risk of post-partum hemorrhage. J Prenat Med. 2013 Jan;7[1]:12-8. PMID: 23741542.

25. Leung SW, Ng PS, Wong WY, Cheung TH. A randomized trial of carbetocin versus syntometrine in the management of the third stage of labour. BJOG. 2006 Dec; 113[12]:1459-64. DOI: 10.1111/j.14710528.2006.01105.x.

26. Su LL, Rauff M, Chan YH, Mohamad Suphan N, Lau TP, Biswas A, Chong YS. Carbetocin versus syntometrine for the third stage of labour following vaginal delivery--a double-blind randomised controlled trial. BJOG. 2009 Oct;116[11]:1461-6. DOI: 10.1111/j.1471-0528.2009.02226.x.

27. Bellad MB, Tara D, Ganachari MS, Mallapur MD, Goudar SS, Kodkany BS, Sloan NL, Derman R. Prevention of postpartum haemorrhage with sublingual misoprostol or oxytocin: a double-blind randomised controlled trial. BJOG. 2012 Jul;119[8]:975-82; discussion $\quad 982-6 . \quad$ DOI: $\quad 10.1111 / j .1471-$ 0528.2012.03341.x. 


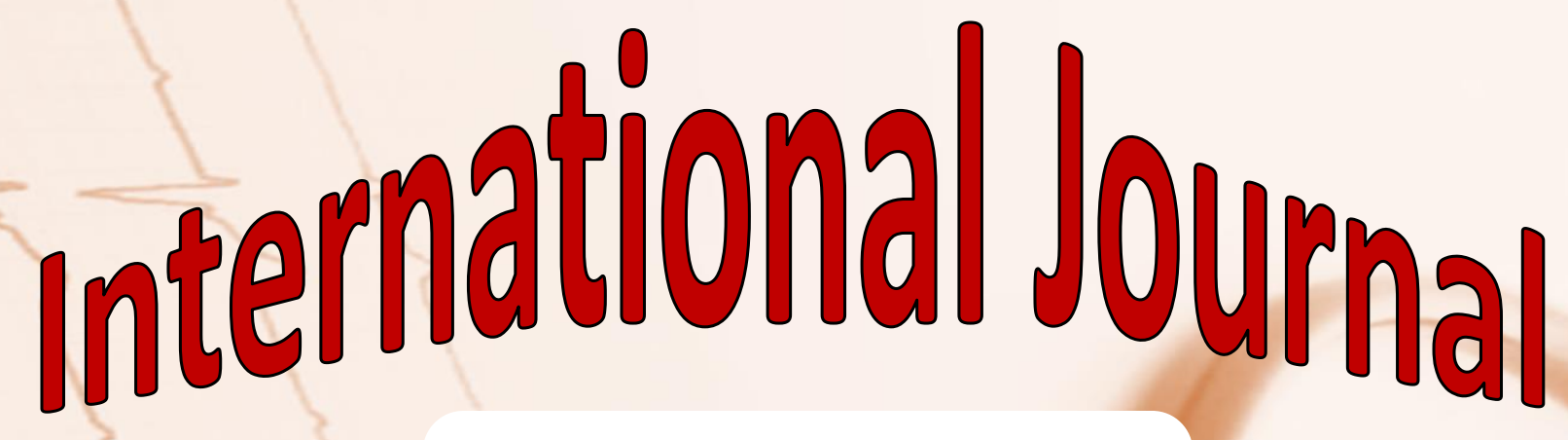

https://ijma.journals.ekb.eg/ Print ISSN: 2636-4174 Online ISSN: 2682-3780

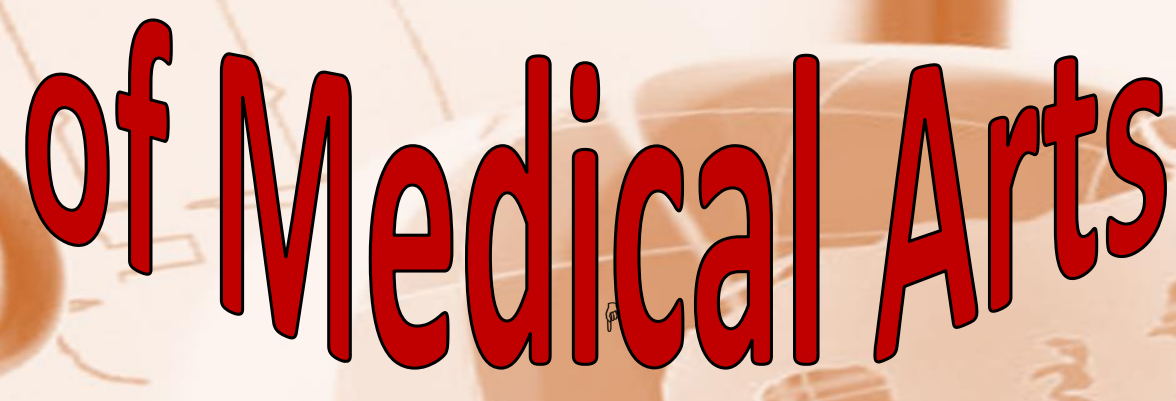

